\title{
Validation of ecoregion-based taper equations for white spruce in Alberta
}

\author{
by Shongming Huang ${ }^{1}$, Stephen Titus ${ }^{2}$, Daryl Price ${ }^{1}$ and Dave Morgan ${ }^{1}$
}

Ecoregion-based variable-exponent taper equations for white spruce (Picea glauca (Moench) Voss) were validated on independent tree sectioning data sets. Criteria used for model validation were briefly reviewed, along with applicable interpretations. Examination of the validation plots and statistics indicated that the mean prediction biases were small and very close to zero $(-0.0058 \leq \overline{\mathrm{e}}$ $\leq 0.0247 ;-0.03 \% \leq \overline{\mathrm{e}} \% \leq 0.20 \%$ ), and the mean squared error of prediction was low. The agreement between observed and predicted values from the taper equations was strong and obvious, and was consistent across the size classes of the predicted values. Approximately $99 \%$ of the total variation in both the diameter inside bark predictions and volume predictions were explained by the application of the fitted taper equations.

Key words: model validation, accuracy and precision, taper function, Picea glauca

\section{Introduction}

In order to differentiate stem form variabilities among different geographic regions, Kozak's (1988) variable-exponent taper equation [1] was fitted by ecoregion (also termed natural subregion within Alberta):

$$
\begin{aligned}
& \text { [1] } d_{i}=a_{0} D^{a 1} a_{2}^{D} \\
& {\left[\left(1-\sqrt{h_{i} / H}\right) /(1-\sqrt{P})\right]^{b_{1} z^{2}+b_{2} \ln (z+0.001)+b_{3} \sqrt{z}+b_{4} e^{z}+b_{5}(D / H)}+\xi_{i}}
\end{aligned}
$$

where $d_{\mathrm{i}}$ is the diameter inside bark $(\mathrm{cm})$ at $h_{\mathrm{i}}, h_{\mathrm{i}}$ is the height (m) above the ground $\left(0 \leq h_{\mathrm{i}} \leq H\right), H$ is the total tree height (m), $D$ is the diameter at breast height outside bark (cm), $z$ is the ratio $h_{\mathrm{i}} / H, e \approx 2.718282, \xi_{\mathrm{i}}$ is random error, $\mathrm{a}_{0}, \mathrm{a}_{1}, \mathrm{a}_{2}, \mathrm{~b}_{1}$, $\mathrm{b}_{2}, \mathrm{~b}_{3}, \mathrm{~b}_{4}, \mathrm{~b}_{5}$, and $p$ are parameters estimated using nonlinear least squares techniques. Regional differences among the taper equations were evaluated using the nonlinear extra sum of squares procedure (Huang 1994). Judging from the fit statistics (Table 1) and residual plots, [1] fitted regionalized white spruce (Picea glauca (Moench) Voss) data well. More than $98 \%$ of the total variability in the dependent variable diameter inside bark was explained by the fitted model within each subregion.

However, because the quality of fit does not necessarily reflect the quality of predictions (Myers 1990), an assessment of its validity on an independent data set is desirable. If the prediction statistics from the validation data set are much different from the fit statistics obtained from the model fitting data set, one may either reject the taper equation, or, as Neter et al. (1990)

\footnotetext{
${ }^{1}$ Forest Management Division, Land and Forest Service, Alberta Environmental Protection, 8th FL., 9920-108 Street, Edmonton, Alberta T5K 2M4.

${ }^{2}$ Department of Renewable Resources, University of Alberta, Edmonton, Alberta T6G $2 \mathrm{H} 1$.
}

Les équations de défilement à exposant variable reposant sur les éco-régions pour l'épinette blanche (Picea glauca (Moench) Voss) ont été validées d'après des séries de données recueillies sur des sections indépendantes d'arbres. Les critères utilisés pour la validation du modèle ont été brièvement révisés, ainsi que les interprétations applicables. L'étude des parcelles et des statistiques a indiqué que les biais moyens de prédiction étaient faibles et très près de zéro $(-0.0058 \leq$ é $\leq 0.0247 ;-0.03 \% \leq$ é $\% \leq 0.20 \%)$, et la déviation quadratique moyenne de la prédiction était faible. Cet accord entre les valeurs observées et prédites à partir des équations de défilement était ferme et évident, était constant entre les classes de dimensions des valeurs prédites. Près de $99 \%$ de la variation totale des prédictions pour le diamètre sans écorce et les prévisions des volumes a été expliquée par l'application des équations adéquates de défilement.

Mots-clés: validation de modèle, précision, fonction de défilement, Picea glauca

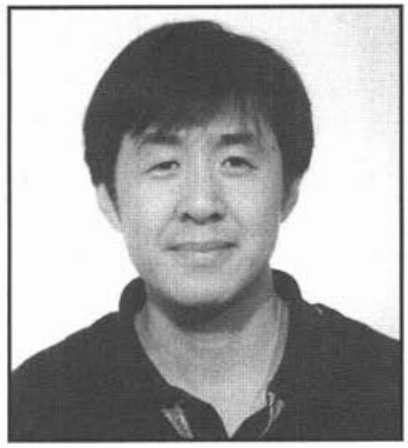

Shongming Huang

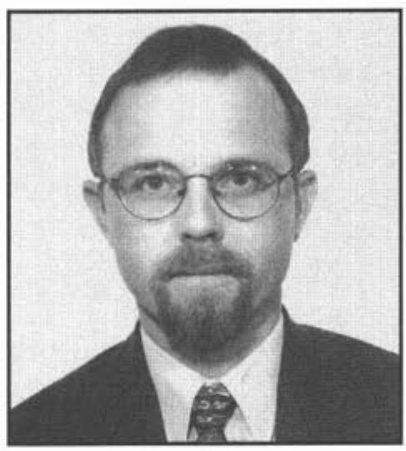

Daryl Price

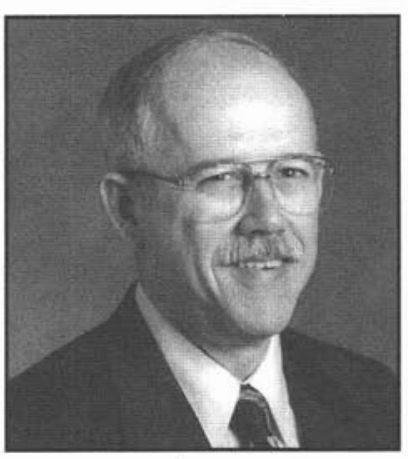

Stephen Titus

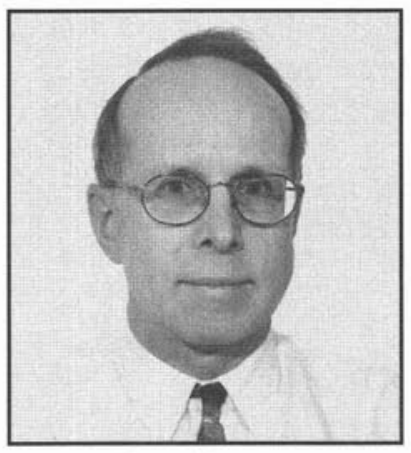

Dave Morgan

suggest, rely on prediction statistics rather than fit statistics as an indication of how well the taper equation will predict in future applications.

The basic idea behind model validation is to see whether or not a fitted model gives an acceptable performance when it is 
Table 1. Fit statistics for the taper equation [1] by subregions

\begin{tabular}{lrrrr}
\hline & \multicolumn{4}{c}{ Subregion } \\
\cline { 2 - 5 } Parameter & \multicolumn{1}{c}{$\mathbf{1}$} & \multicolumn{1}{c}{$\mathbf{3}$} & \multicolumn{1}{c}{$\mathbf{1 0}$} & \multicolumn{1}{c}{$\mathbf{1 1}$} \\
\hline$a_{0}$ & 0.922171 & 0.957851 & 1.063410 & 0.882113 \\
$a_{1}$ & 0.983483 & 0.971624 & 0.963385 & 1.005300 \\
$a_{2}$ & 0.998782 & 1.000295 & 1.000747 & 0.998695 \\
$b_{1}$ & 1.223995 & 1.047993 & 2.301465 & 1.219332 \\
$b_{2}$ & -0.291693 & -0.286789 & -0.583724 & -0.282259 \\
$b_{3}$ & 2.078849 & 1.820599 & 3.618578 & 1.888893 \\
$b_{4}$ & -1.016832 & -0.851763 & -2.026543 & -0.959053 \\
$b_{5}$ & 0.124947 & 0.084314 & 0.186098 & 0.149403 \\
$p$ & 0.171978 & 0.108458 & 0.044504 & 0.138279 \\
& & & & \\
$n$ & 6509 & 1837 & 3205 & 6654 \\
MSE & 1.3769 & 0.7522 & 2.0856 & 1.9214 \\
$R^{2}$ & 0.9888 & 0.9913 & 0.9877 & 0.9881 \\
\hline
\end{tabular}

Note: MSE and $R^{2}$ are mean squared error and coefficient of determination, $\mathrm{n}$ is the total number of observations.

Subregion 1 = central mixedwood; Subregion 3 = wetland mixedwood; Subregion $10=$ upper foothills; Subregion $11=$ lower foothills.

used for prediction. The difficulty is that there is no single or best answer to such a question. Balci and Sargent (1984) listed a total of 308 references dealing with different ways of model validation. Various alternative approaches have appeared in the forestry literature (Freese 1960, Ek and Monserud 1979, Reynolds and Chung 1986, Kozak and Smith 1993, Vanclay and Skovsgaard 1997), and have been used in a variety of settings (Rennie and Wiant 1978, Reynolds et al. 1981, Gál and Bella 1995, Soares et al. 1995; Rykiel 1996). The main purpose of this study is to suggest a set of criteria for validating regression models and use them to validate the predictive performance of the regionalized taper equations fitted for white spruce in Alberta.

\section{Material and Methods}

Stem analysis data from a total of 871 sectioned white spruce trees were used as the validation data. The data cover four major commercial timber production regions in Alberta: the central mixedwood (subregion 1), the wetland mixedwood (subregion 3 ), the upper foothills (subregion 10) and the lower foothills (subregion 11). A more detailed description of the data can be found in Alberta Forest Service (1988). A summary of the data by height and diameter class is shown in Table 2 .

The potential problem of heteroskedasticity (heterogeneous variances) and inherent dependence (correlation) of the stem analysis data, arising from taking several measurements from the same trees at different heights, may invalidate stan- dard regression hypothesis testing procedures and interval estimations. The problem can be solved using generalized nonlinear least squares (GNLS) methods and nonlinear mixed model techniques as demonstrated by Huang et al. (1997) and Huang (1997) on similar data. However, for prediction purpose, whether or not the correlation and heteroskedasticity is accounted for has little practical significance (Kozak 1997, Huang et al. 1997). A "do-nothing" approach is usually the best for practitioners whose primary concern is to achieve best predictions rather than best statistical inferences on transformed data and matrices in a repeated sampling sense (Huang 1997).

A total of six criteria were used for validating regionalized taper equations. A brief description of these criteria follows:

Criterion 1 - The mean prediction bias (e) and percent bias (e\%).

The mean prediction bias calculated by [2] is defined as the arithmetic average of the prediction errors. It is often expressed as a percentage bias $(\overline{\mathrm{e}} \%)$ shown in [3]:

[2] $\bar{e}=\frac{\sum_{i=1}^{n}\left(y_{i}-\hat{y}_{i}\right)}{n}=\frac{\sum e_{i}}{n}$

[3] $\bar{e} \%=\frac{\bar{e}}{\bar{y}} \times 100=\frac{\bar{e}}{\sum y_{i} / n} \times 100$

where $n$ is the total number of observations in the validation data set, $\mathrm{e}_{\mathrm{i}}$ is the $i$ th prediction error $\left(\mathrm{e}_{\mathrm{i}}=\mathrm{y}_{\mathrm{i}}-\hat{\mathrm{y}}_{\mathrm{i}}\right), \mathrm{y}_{\mathrm{i}}$ is the $i$ th observed value of the variable in interest and $\hat{y}_{i}$ is its prediction from the estimated model $(i=1,2, \ldots, n), \overline{\mathrm{y}}$ is the average of the observed values $\left(\bar{y}=\sum y_{i} / n\right)$.

The mean prediction bias ( $\overline{\mathrm{e}}$ ) and the percent bias ( $\overline{\mathrm{e}} \%$ ) provide two most intuitive measures as to the sizes of the difference between observed and predicted values. Both take account of the signs of the prediction errors. However, they have several potential deficiencies. The deficiencies are caused, not by any flaw in the computation itself, but by the possible misinterpretations incurred from the calculated results. As an example, if $\overline{\mathrm{e}}$ (or $\overline{\mathrm{e}} \%$ ) is close to zero, one may state that the model provides "unbiased" predictions, and hence, it is "correct" and can be used for predictions. This may lead to the acceptance of a poor model as illustrated in Figures 1(c) and 1(d), where the $\overline{\mathrm{e}}$ in each case could be zero if the negative and positive errors below and above the line were averaged. In an extreme case, if the data in Figure 1(c) is perpendicular to the line, $\overline{\mathrm{e}}$ could still be zero when all $\mathrm{e}_{\mathrm{i}}$ 's were averaged.

Criterion 2 - Plot of prediction errors $\left(\mathrm{e}_{\mathrm{i}}\right)$ versus predicted values $\left(\hat{y}_{\mathrm{i}}\right)$.

\begin{tabular}{|c|c|c|c|c|c|c|c|c|c|}
\hline \multirow[b]{2}{*}{ Subregion } & \multirow[b]{2}{*}{ No. of trees } & \multicolumn{4}{|c|}{$D(\mathrm{~cm})$} & \multicolumn{4}{|c|}{$H(\mathrm{~m})$} \\
\hline & & Mean & Min. & Max. & Std. dev. & Mean & Min. & Max. & Std. dev. \\
\hline 1 & 328 & 25.184 & 1.200 & 64.300 & 11.4352 & 19.650 & 1.700 & 35.360 & 6.5038 \\
\hline 3 & 87 & 19.023 & 1.800 & 38.000 & 8.5489 & 17.905 & 2.240 & 30.060 & 6.7035 \\
\hline 10 & 156 & 24.852 & 1.500 & 70.800 & 12.0920 & 17.4831 & 2.190 & 34.600 & 7.4216 \\
\hline 11 & 300 & 30.051 & 1.400 & 68.100 & 12.4249 & 22.444 & 1.840 & 37.900 & 7.0275 \\
\hline Combined & 871 & 26.186 & 1.200 & 70.800 & 12.1020 & 20.050 & 1.700 & 37.900 & 7.1278 \\
\hline
\end{tabular}

Note: $H=$ total tree height $(\mathrm{m}) ; D=$ diameter at breast height outside bark $(\mathrm{cm}) ;$ Min.=minimum; Max.=maximum; Std. dev.=standard deviation. Subregion 1 $=$ central mixedwood; Subregion $3=$ wetland mixedwood; Subregion $10=$ upper foothills; Subregion $11=$ lower foothills. 


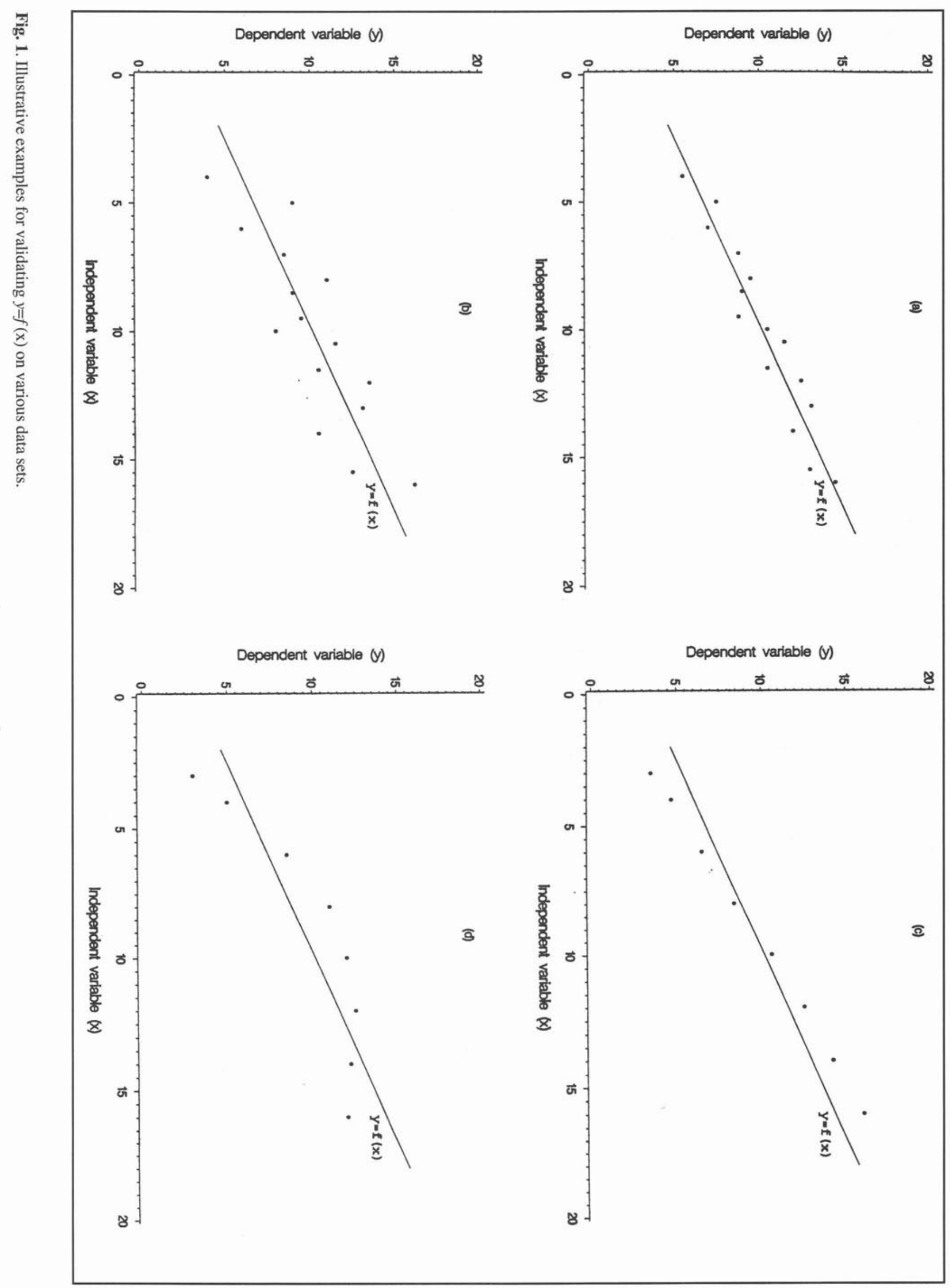


To minimize the problems associated with Criterion 1, the prediction errors $\left(\mathrm{e}_{\mathrm{i}}\right)$ should be plotted against the predicted values $\left(\hat{y}_{\mathrm{i}}\right)$ from the model. This "plot of prediction errors" on the validation data set is similar in concept to the "plot of residuals" on the model fitting data set. It is one of the most powerful, yet simple and obvious criteria for judging the prediction performance of any regression model.

The plot of observed values $\left(\mathrm{y}_{\mathrm{i}}\right)$ versus predicted values $\left(\hat{\mathrm{y}}_{\mathrm{i}}\right)$ serves the same purpose as the plot of prediction errors. If the model is correct, the plot of $y_{i}$ versus $\hat{y}_{i}$ shows an homogeneous upward band of the data points, with its slope equal to 45 degrees. A straight line of $y_{i}=\hat{y}_{i}$ should pass through the centres of the data points. Any peculiar data pattern as illustrated in Figures 1 (c) and 1(d) can be detected from the plot of observed versus predicted values, or from the plot of prediction errors.

With the plotting techniques discussed above, obvious patterns of deviation from the norms are easy to spot, especially when the sample size of the validation data set is relatively large. If the patterns are not clear, statistical methods may be required to determine whether or not the deviations are serious. Two such methods were recommended by Ek and Monserud (1979). The first one involves the fitting of simple linear models between observed and predicted values, using $\mathrm{y}_{\mathrm{i}}$ $=a+b \hat{y}_{i}$, where $a$ and $b$ are parameters to be estimated. The appropriateness of the model to be validated is determined by testing the null hypothesis that $a=0$ and $b=1$. A more recent example of a similar approach is shown in Keeland and Sharitz (1993).

The second method involves the fitting of models between prediction errors and $\mathrm{x}$-variables, using for example, $\mathrm{e}_{\mathrm{i}}=\mathrm{b}_{0}$ $+\mathrm{b}_{1} \mathrm{x}_{1}+\mathrm{b}_{2} \mathrm{x}_{2}$, or $\mathrm{e}_{\mathrm{i}}=f(\mathrm{x}$ 's), where b's are parameters to be estimated. This method is also discussed by Reynolds and Chung (1986).

A simple modification to the above methods is to fit regression functions between $e_{i}$ and $\hat{y}_{i}$, using for example, $e_{i}=$ $a+b \hat{y}_{i}$ or $e_{i}=a+b \hat{y}_{i}+c \hat{y}_{i}{ }^{2}$. The latter could be used to detect whether or not a curvature form of the prediction errors, such as that related to the data illustrated in Figure 1(d), is presented. The conditions for unbiased predictions in this case become: $\mathrm{a}=\mathrm{b}=\mathrm{c}=0$. In some more complex circumstances where the data display other peculiar patterns, more complicated functional forms between $e_{i}$ and $\hat{y}_{i}$ may be required. Some high order polynomials or nonlinear models may be used.

Criterion 3 - The mean squared error of prediction (MSEP) and relative error in prediction (RE\%).

The MSEP is defined as the mean of the squared prediction errors. It is calculated according to [4]:

[4] MSEP $=\left[\sum_{i=1}^{n}\left(y_{i}-\hat{y}_{i}\right)^{2}\right] / n$

The relative error in prediction (RE\%) that expresses the MSEP on a relative scale, relative to the "true" mean $\bar{y}$ $\left(\bar{y}=\sum y_{i} / n\right)$ of the validation data set, can be calculated as shown in Rawlings (1988, p.188):

\section{[5] $R E \%=\sqrt{M S E P} / \bar{y} \times 100$}

Criterion 4-The coefficient of determination.

The coefficient of determination on the validation data set, $\mathrm{R}_{\mathrm{v}}{ }^{2}$, is calculated by:
[6] $R_{v}^{2}=1-\left[\sum_{i=1}^{n}\left(y_{i}-\hat{y}_{i}\right)^{2}\right] /\left[\sum_{i=1}^{n}\left(y_{i}-\bar{y}\right)^{2}\right]$

The calculated $\mathrm{R}_{\mathrm{v}}{ }^{2}$ reflects the proportion of variation in the validation data set that is accounted for in the predictions. A higher $\mathrm{R}_{\mathrm{v}}{ }^{2}$ value indicates a better goodness-of-prediction for the validation data set.

Criterion 5 - Prediction errors across different size classes of selected variables.

The criteria and the related statistics discussed so far provide "averaged" measures regarding the overall prediction performance of the taper equations. Sometimes, the prediction performance of the taper equations at different parts of the tree, or for different tree sizes, may need to be examined as well (Kozak and Smith 1993). In such cases, the prediction errors can be plotted against the variables of interest, and the validation statistics can be calculated by some pre-selected size classes (or strata) of the variables.

\section{Criterion 6-Prediction errors for variables derived from taper} equations.

Since the $y$-variable in the taper equation is diameter inside bark, validation of diameter inside bark predictions is considered the most important. However, there are many other variables that can be derived from the taper equation. Among them, gross total tree volume, merchantable length, merchantable height, merchantable volume, and log volume are most common. It is important to find whether their predictions derived from the taper equation are adequate.

\section{Results}

Because of its simplicity and power in revealing the prediction performance, the plots of prediction errors were examined first. Diameter inside bark prediction errors, calculated and plotted as described in Criterion 2, show a horizontal band of the data points symmetrically scattered around zero (Figure 2), with no obvious tendency to be positive or negative. The magnitudes of the prediction errors are, more or less, the same across the size classes of the predicted values for all four subregions. Fitting of regression models between the prediction errors and the predicted values resulted in $\mathrm{R}^{2}$ values of $0.0078,0.0110,0.0293$, and 0.0063 , corresponding to subregions $1,3,10$, and 11 , respectively. These $\mathrm{R}^{2}$ values are very low, and the relationships they represent (in Figure 2) can be regarded as non-existent.

A summary table (Table 3 ) shows the calculated statistics related to the model validation criteria is provided. The mean prediction biases are very small, both in absolute values $(-0.0058$ $\leq \overline{\mathrm{e}} \leq 0.0247)$ and in percent values $(-0.03 \% \leq \overline{\mathrm{e}} \% \leq 0.20 \%)$. All are very close to zero. These are strong indications that the taper equations accommodated the validation data sets well.

The MSEP values described in Criterion 3 are fairly close to the MSE values in the corresponding subregions (Table 3 ). The relative efficiency ratios are all less than $2\left(\mathrm{r}_{\mathrm{E}}<2\right)$. The MSEPs of the taper equations were found to be predominantly determined by the precision of predictions (i.e., the variance of prediction), rather than the bias of prediction. Based on these observations, one can state that the mean prediction biases are small and the taper equations predicted diameter inside bark well for all four subregions. The relative errors in prediction (RE\% in [5]), shown in Table 3, are 7.68\%, 6.39\%, $11.26 \%$ 


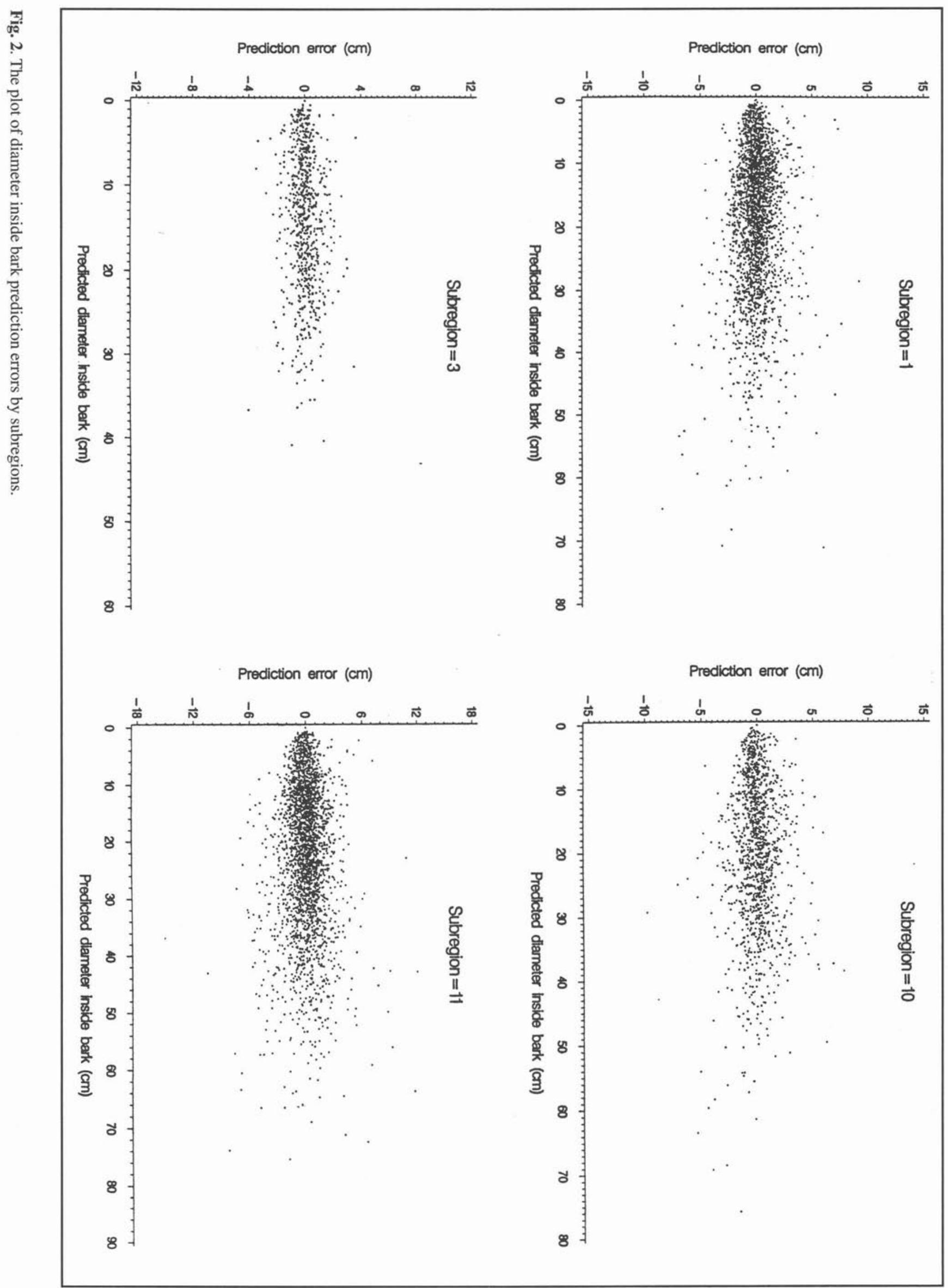


Table 3. Summary of the validation statistics for diameter inside bark predictions by subregions

\begin{tabular}{|c|c|c|c|c|c|}
\hline Criterion & Relevant formula & Subregion 1 & Subregion 3 & Subregion 10 & Subregion 11 \\
\hline $\mathrm{n}$ & & 3090 & 835 & 1499 & 3363 \\
\hline$\overline{\mathrm{e}}$ & {$[2]$} & 0.0206 & 0.0247 & -0.0058 & 0.0217 \\
\hline$\overline{\mathrm{e}} \%$ & [3] & 0.13 & 0.20 & -0.03 & 0.11 \\
\hline MSEP & [4] & 1.4893 & 0.6309 & 1.9496 & 2.3732 \\
\hline RE\% & [5] & 7.68 & 6.39 & 11.26 & 7.96 \\
\hline $\mathrm{R}_{\mathrm{v}}{ }^{2}$ & [6] & 0.9886 & 0.9917 & 0.9877 & 0.9868 \\
\hline $\mathrm{r}_{\mathrm{E}}$ & & 1.0816 & 0.8387 & 0.9348 & 1.2351 \\
\hline
\end{tabular}

Note: Definitions of criteria and relevant formulas are provided in the main text. $\mathrm{r}_{\mathrm{E}}=\mathrm{MSEP} / \mathrm{MSE}$. Subregion $1=$ central mixedwood; Subregion $3=$ wetland mixedwood; Subregion $10=$ upper foothills; Subregion 11 = lower foothills.

and $7.96 \%$. All are found to be slightly larger than the corresponding values from model fitting data sets except for subregion 3.

The $\mathrm{R}_{\mathrm{v}}{ }^{2}$ values calculated on the validation data sets are 0.9886 , $0.9917,0.9877$, and 0.9868 , for subregions $1,3,10$, and 11 , respectively (Table 3 ). All are close to the corresponding $\mathrm{R}^{2} \mathrm{~s}$ from the model fitting data sets. This is a strong indication that the percentages of the total variability in the validation data sets explained by the application of the fitted taper equations are high, and the agreement between observed and predicted diameter inside bark is good and consistent for all four subregions.

Figure 3 shows the prediction errors plotted against the four independent variables used in the taper equations for the example subregion with the most data (Criterion 5). The plots for other subregions are similar. These plots provide informative displays of how well the taper equations perform at different parts of the tree (prediction errors versus $h$, and prediction errors versus $z$ ), or for different tree sizes (prediction errors versus $D$, and prediction errors versus $H$ ). In general, the data points in Figure 3 indicate no obvious trend to suggest overestimation or underestimation across the size classes of the selected independent variables, an indication that the taper equations perform reasonably well.

Validation statistics compatible with Figure 3 were calculated by some pre-selected size classes of the independent variables (Table 4). Other validation statistics can be calculated in a similar manner, and other size classes of the $\mathrm{x}$-variables can also be used. Results in Table 4 suggest that the optimum validation statistics indicative of the best diameter inside bark predictions (in terms of minimum $\overline{\mathrm{e}}, \overline{\mathrm{e}} \%$ and MSEP value) vary with tree size $(\mathrm{D}, \mathrm{H})$ and perhaps along the stem. Almost all bias of any predictive significance occurs near the top of very large or very small trees. In general, however, the majority of the prediction biases are quite small.

The plots of observed gross total volumes versus predicted volumes for trees greater than $2 \mathrm{~cm}$ in diameter $(D>2$ $\mathrm{cm}$ ) are shown in Figure 4 (Criterion 6). The observed true volumes of the sectioned trees are calculated using Smalian's formula (Husch et al. 1982), and the predicted volumes are calculated by sectioning the tree into small sections and then use the Newton's formula to sum up the section volumes (Huang 1994). The agreement between the observed and predicted gross total tree volumes is obvious from Figure 4. Within each subregion the magnitude of the volume prediction biases across the size classes of the predicted volumes is roughly the same, except for two large trees in subregion 10 (Figure 4). Selected validation statistics concerning the gross total vol- ume predictions are shown in Table 5. The bias values range from 0.0012 to 0.0074 . The percentage values range from $0.2027 \%$ to $1.7072 \%$. These values are small, indicating that the tree volume prediction biases from the taper equations are not substantial for all subregions. The $\mathrm{R}_{\mathrm{v}}{ }^{2}$ values for the volume predictions are very high (range from 0.9845 to 0.9894 ). Note that the volume prediction biases and consequently the percent prediction biases, are all positive (Table 5). This is probably caused by the fact that the observed "true" volumes of the sectioned trees, calculated using the Smalian's formula, are slightly overestimated (Husch et al. 1982, Kozak 1988, Huang 1994).

Another variable of interest related to Criterion 6 is merchantable height $(M H)$, which is defined as the height above the ground to the specified utilization standard. The $M H$ corresponds to $h$ in the taper equation $d=f(h, H, D)$. It is related to merchantable length $(M L)$ through: $M H=M L+S H$, where $S H$ is the stump height above the ground (usually set at $0.3 \mathrm{~m}$ in Alberta, Huang 1994). A diameter at breast height of $9.0 \mathrm{~cm}$ outside bark and a merchantable length of $3.0 \mathrm{~m}$ are considered as the minimum utilizable tree size in this study.

For each tree greater than $9.0 \mathrm{~cm}$ in diameter $(D>9.0)$, the observed height above the ground $(h)$ at the top of each section above $3.0 \mathrm{~m}$ is compared to its prediction from the taper equation. The prediction is obtained by solving $h$ from $d=f(h$, $H, D$ ), through an iterative procedure described in Huang (1994). This allows various $h$ values observed along the stem to be compared with the predictions from the taper equation, and therefore, is more informative than if a fixed $h$ or relative height value (e.g., at $80 \%$ or $90 \%$ of total height) is used. A graph showing the observed versus predicted heights above the ground is shown in Figure 5. Once again, the agreement between observed and predicted heights is strong.

Similarly, for trees greater than $9.0 \mathrm{~cm}$ in diameter, merchantable volumes from stump height to any $h$ above $3.0 \mathrm{~m}$ were calculated, and then compared to those predicted from the appropriate regionalized taper equation. A graph of observed versus predicted merchantable volumes was very similar to Figure 4, showing a strong agreement between observed and predicted values. Additional plots of other variables also indicated strong agreements between observed and predicted values.

\section{Discussion}

The discussion section presented here relates to the role of statistical tests in model validation. The quantities calculated from the validation criteria shown in this study provided the basis for determining how well the fitted model performed on the 


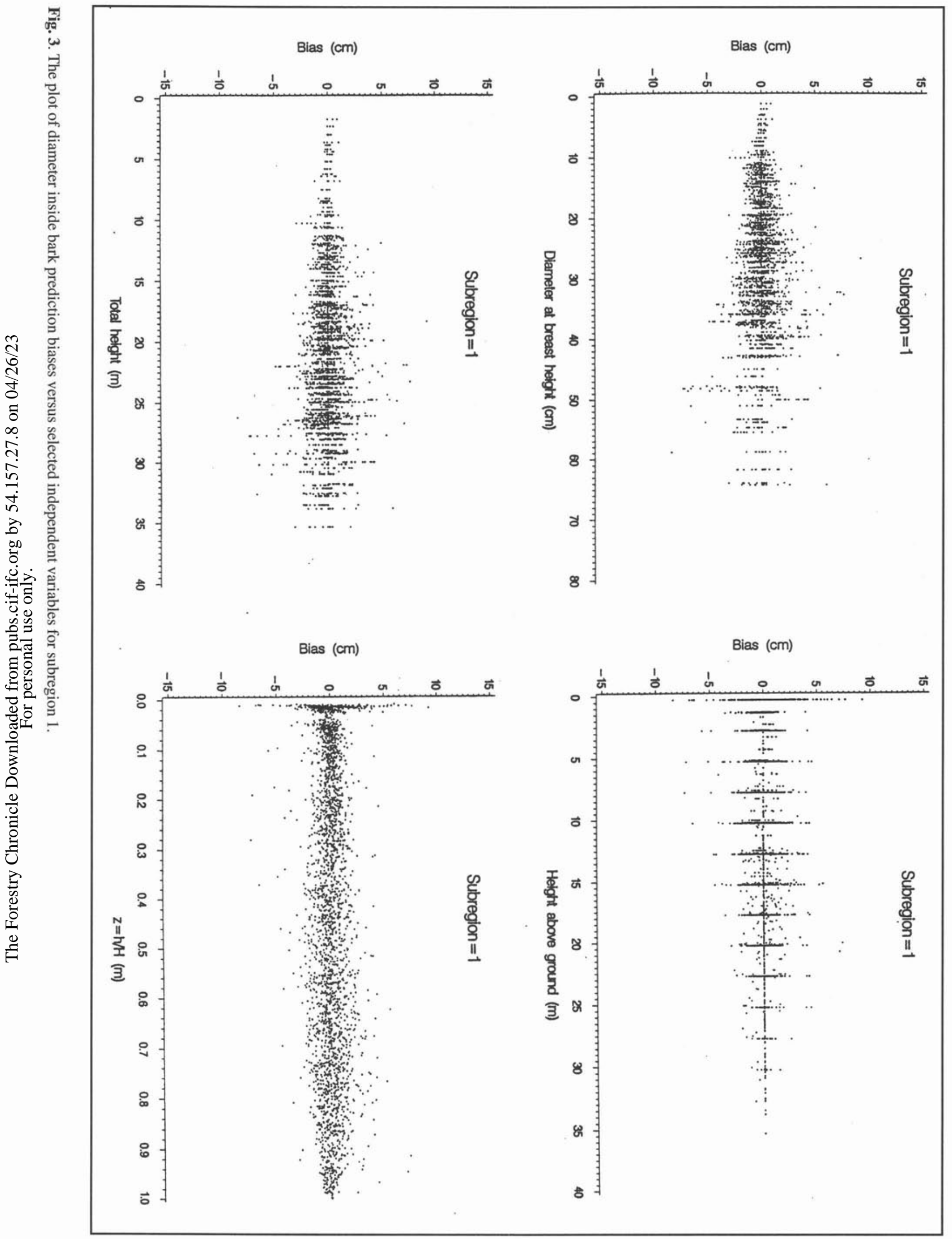




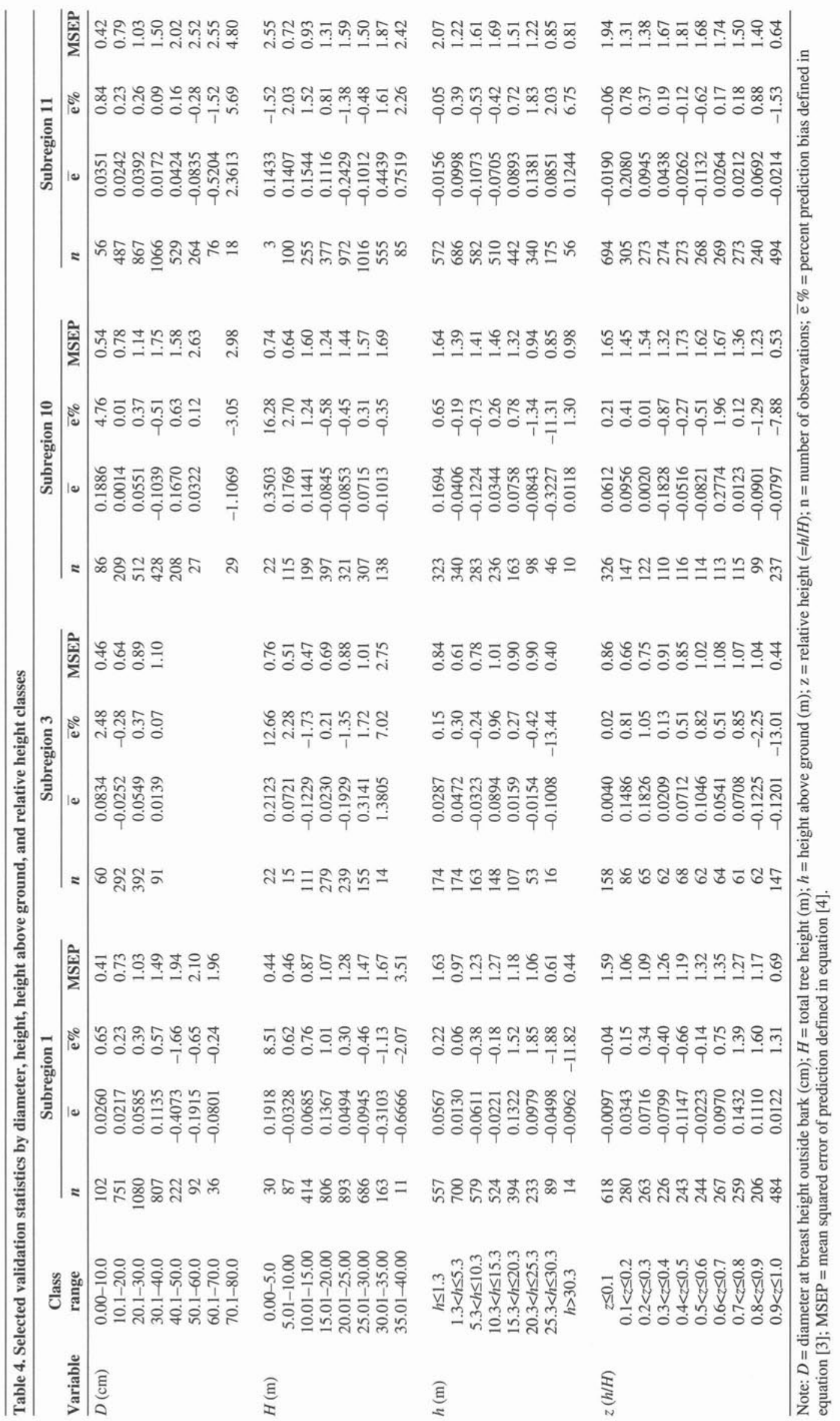



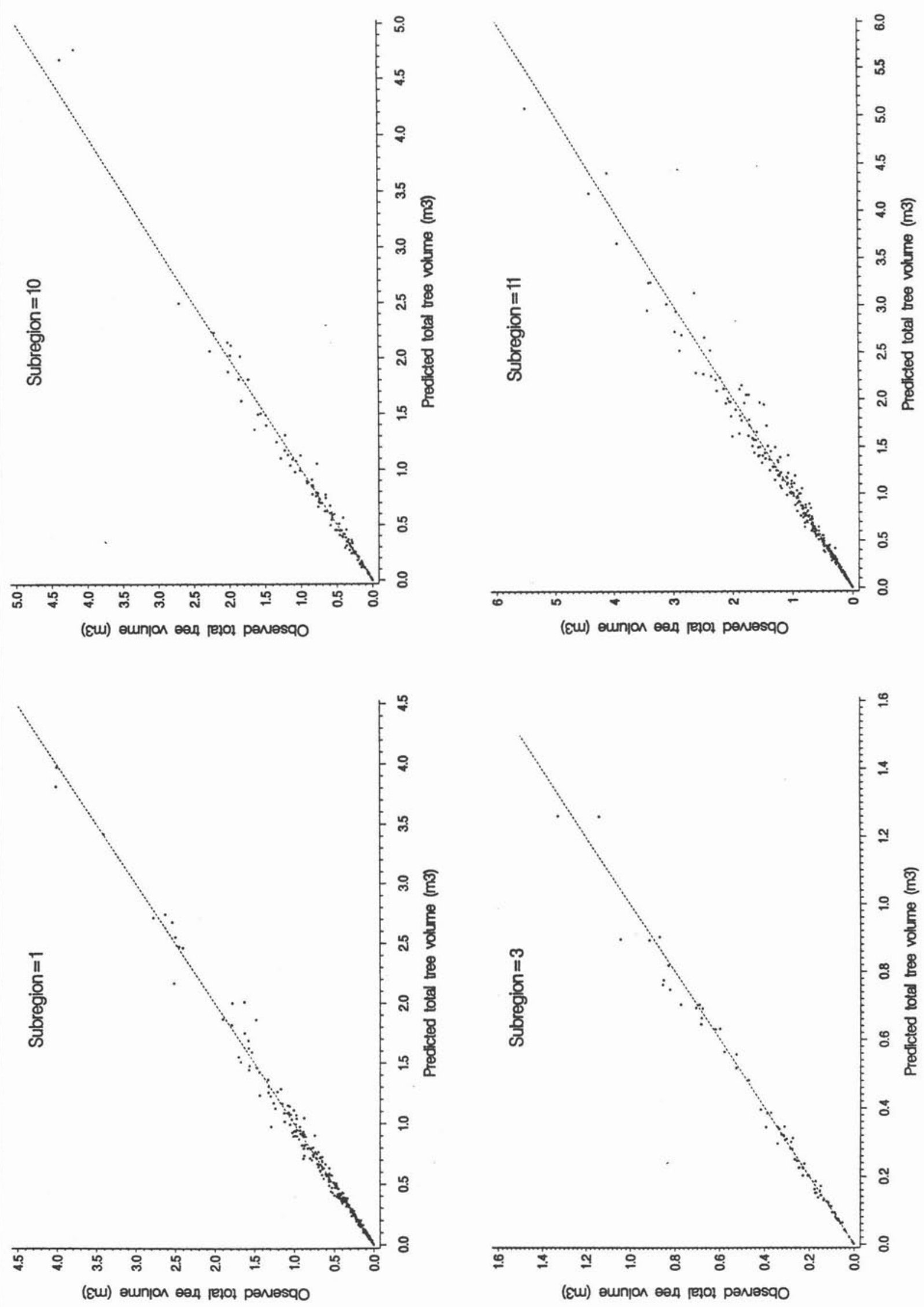

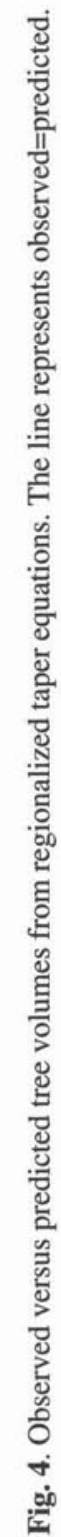




\begin{tabular}{|c|c|c|c|c|c|c|c|c|c|}
\hline Subregion & Variable & No. of trees & Mean & Minimum & Maximum & std. dev. & $\overline{\mathrm{e}} \%$ & MSEP & $\mathbf{R}_{\mathrm{v}}{ }^{2}$ \\
\hline \multirow[t]{3}{*}{1} & bias & 325 & 0.0029 & -0.3837 & 0.3478 & 0.0620 & 0.5166 & 0.0628 & 0.9894 \\
\hline & vol & 325 & 0.5614 & 0.0005 & 4.0112 & 0.6026 & & & \\
\hline & vôl & 325 & 0.5585 & 0.0003 & 3.9796 & 0.6031 & & & \\
\hline \multirow[t]{3}{*}{3} & bias & 85 & 0.0054 & -0.1209 & 0.1470 & 0.0314 & 1.7072 & 0.0335 & 0.9887 \\
\hline & vol & 85 & 0.3163 & 0.0006 & 1.3272 & 0.3000 & & & \\
\hline & vôl & 85 & 0.3110 & 0.0005 & 1.2625 & 0.2918 & & & \\
\hline \multirow[t]{3}{*}{10} & bias & 155 & 0.0012 & -0.5321 & 0.2826 & 0.0797 & 0.2027 & 0.0819 & 0.9873 \\
\hline & vol & 155 & 0.5921 & 0.0008 & 4.3635 & 0.7075 & & & \\
\hline & vôl & 155 & 0.5909 & 0.0003 & 4.6996 & 0.7264 & & & \\
\hline \multirow[t]{3}{*}{11} & bias & 295 & 0.0074 & -0.4971 & 0.4799 & 0.1096 & 0.8506 & 0.1096 & 0.9845 \\
\hline & vol & 295 & 0.8700 & 0.0033 & 5.4980 & 0.8356 & & & \\
\hline & vôl & 295 & 0.8625 & 0.0036 & 5.1149 & 0.8147 & & & \\
\hline
\end{tabular}

Note: vol = observed "true" volume $\left(\mathrm{m}^{3}\right)$ calculated from the Smalian's formula; vôl = predicted tree volume $\left(\mathrm{m}^{3}\right)$ calculated using the taper equation; bias $=\left(\operatorname{vol}_{\mathrm{i}}-\mathrm{vô}_{\mathrm{i}}\right)$, where $\mathrm{i}=1,2, \ldots, \mathrm{n}$, and $\mathrm{n}$ is the number of trees; $\overline{\mathrm{e}} \%=$ percent bias defined in equation [3]; MSEP $=$ mean squared error of prediction defined in equation [4]; $\mathrm{R}_{\mathrm{v}}{ }^{2}=$ coefficient of determination defined in equation [6].

validation data sets. However, they did not answer the question of whether or not the predictions are in the "acceptable" ranges. Ideally, the mean prediction bias $\overline{\mathrm{e}}$ calculated by [2] should not differ significantly from zero so that the predictions are "unbiased" on average. A logical step seems to be to find a statistical test that can be used to test (1) if the bias is significantly different from zero; and (2) if the variance of prediction errors is larger than a critical value from a statistical table.

It is a well-known fact that fitted models do not predict new data as well as data used to develop the models (Burk 1990, Montgomery and Peck 1992). Least squares residuals from the model fitting data set are the "best" (i.e., have a zero mean and a minimum variance), and are smaller than the prediction errors from the model validation data set (Neter et al. 1990, Myers 1990). In fact, fit statistics derived from the model fitting data set give an "overly-optimistic" assessment of the fitted model (Picard and Cook 1984, Reynolds and Chung 1986, Neter et al. 1990). The understanding of this so-called "optimism principle" is critical in model validation. What it signifies is that a fitted model can still be acceptable even if it is less accurate and less precise when applied to the validation data set.

In model validation, the inappropriateness of the paired $t$ test procedure for testing whether or not the prediction bias $\overline{\mathrm{e}}$ is significantly different from zero, has been discussed by many (Freese 1960, Ek and Monserud 1979, Reynolds et al. 1981). For instance, if paired $t$-tests were used to validate the models in Figure 1, all models could have been considered appropriate for the given data because the mean prediction biases, and consequently the $t$-values, could all be zero when the negative and positive errors below and above the models were averaged. In a relevant study, Pillsbury et al. (1995) suggested that as long as the prediction bias was less than $12 \%$, a fitted model from one region should be acceptable in another region. Testing whether or not the mean prediction bias equals zero, and using the test result as the criterion for "accepting" or "rejecting" a fitted model, is not exactly relevant in model validation.

The $\chi^{2}$-test of the mean squared errors was suggested as an alternative for testing the accuracy and determining the applicability of forestry models (Freese 1960). Such a test, however, was not used in this study. The main reason for not con- ducting this test is explained by the optimism principle: if a statistic from the validation data is compared or tested against its counterpart from the model fitting data, the result is almost certain to indicate that the model is "poorer" on the validation data, and this may lead one to wrongly believing that the model is inadequate because it produced less accurate or less precise predictions. Montgomery and Peck (1992) and Neter et al. (1990) demonstrated that the MSEP values in two separate validations were approximately two and three times, respectively, larger than the MSE values. However, in both cases, they concluded that the MSEP was not greatly different from MSE, and this (together with other criteria), supported the appropriateness of the fitted models. If a statistical test (such as $\chi^{2}$-test) were conducted, in both cases it would most likely have indicated that the MSEP on the validation data were significantly larger than its counterpart from the model fitting data, since MSEP was more than two times the size of MSE, which could have been taken as evidence to claim that the models were inadequate.

A more complicated situation can occur if one does not know the fit statistics of the original model (except the coefficients) but still wants to verify whether or not, the model provides reasonable predictions. There is a danger of rejecting a good model if a subjective "threshold of acceptance" MSEP is specified. This can be illustrated using Figures 1(a) and 1(b), where the fitted model $y=f(x)$ is validated on two data sets of unequal variation. The model appear adequate for both data sets. However, if a statistical test is conducted, it may indicate, for example, that the model is acceptable in Figure 1(a), but not in Figure 1(b) because it has a larger MSEP. Indeed, it is a very dubious practice in this situation to set up an acceptable value and use it as the standard to validate the model. Statistical tests of "allowable" errors are generally related to sampling problems, but rarely to regression problems.

Berk (1984, p.336) showed that the relative efficiency measure $\left(\mathrm{r}_{\mathrm{E}}\right)$ defined by $\mathrm{r}_{\mathrm{E}}=$ MSEP/MSE can be affected by many factors, and is possible to exceed 2 even when the model predicts well. Many researchers avoid hypothesis testing and recommend instead, that as long as the MSEP is fairly close to MSE, the model should provide an adequate indication as to its predictive capability, and is likely to be suc- 

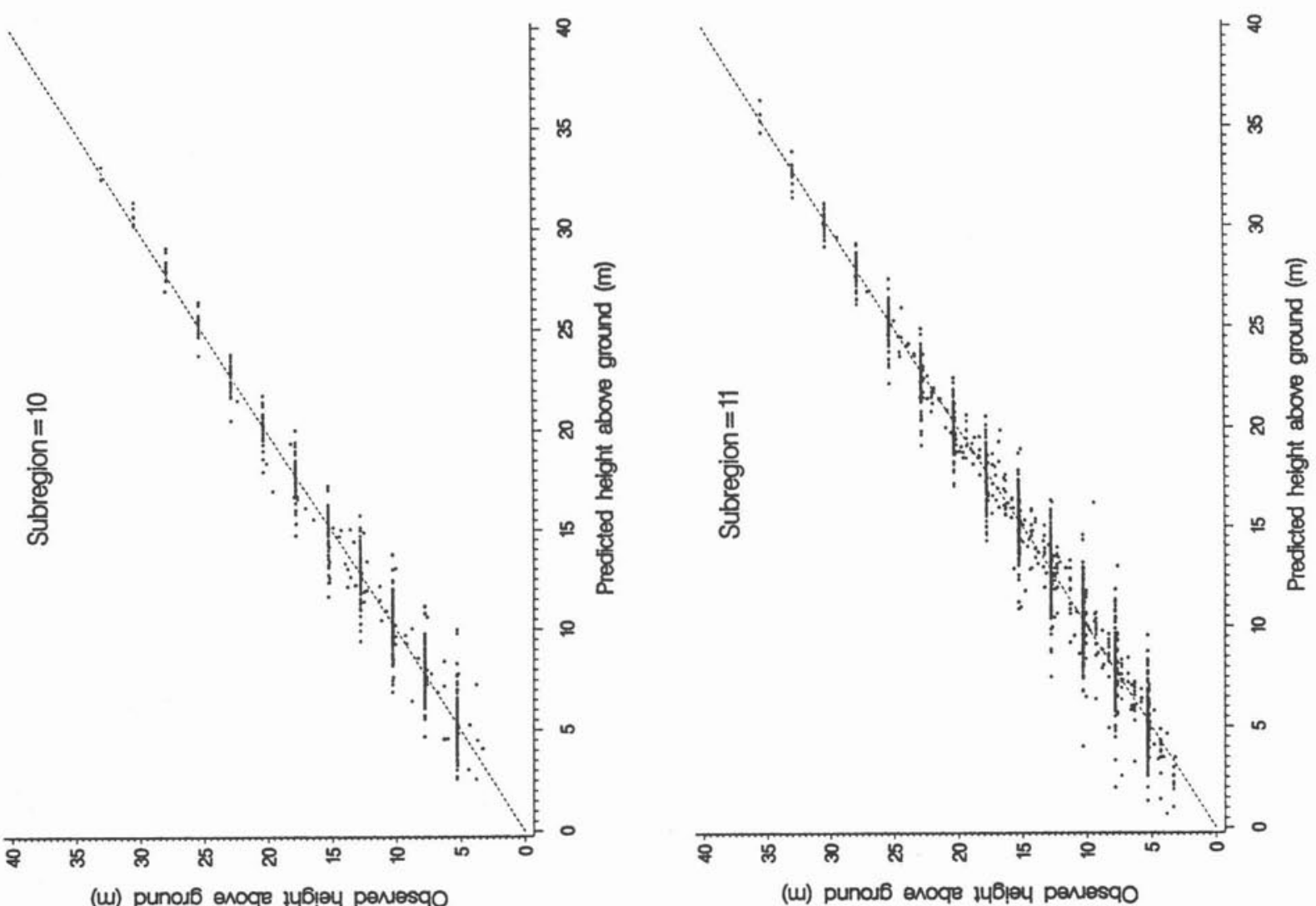

(w) punos6 enoqe 1466 |ө penesqo

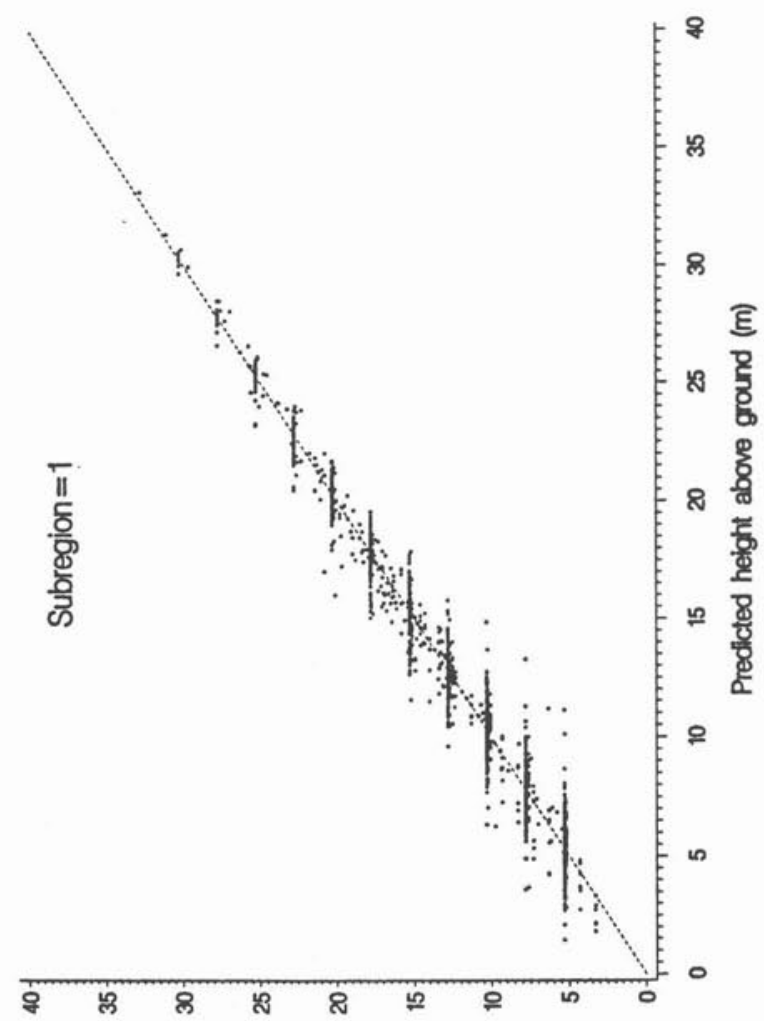

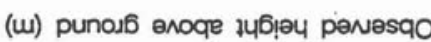

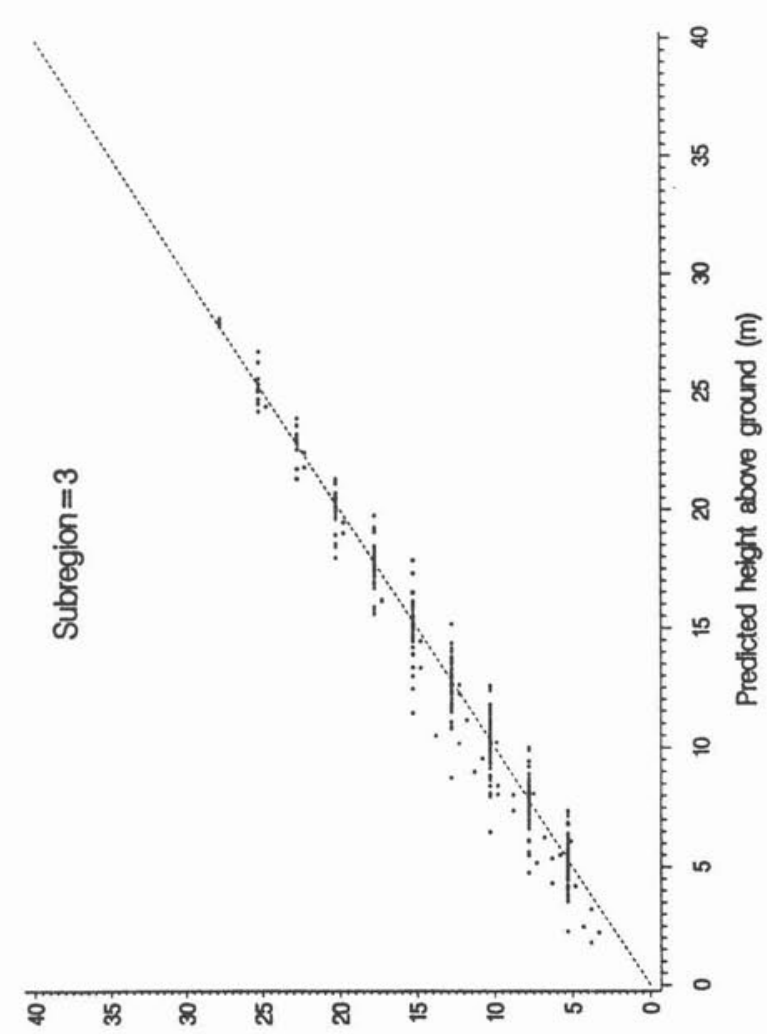

(w) punot6 enoqe 
cessful as a predictor (Montgomery and Peck 1992, Neter $\mathrm{et} \mathrm{al}$. 1990). A general strategy advocated concerning model validation is to see how well the fitted model fits the new data, rather than use a statistic to test whether it is good enough, which is different depending on the strength of the relationship and the objectives of the study. Model validation is a composite process that may involve the use of statistical tests, but tests alone cannot be used as the criterion for deciding the adequacy of a fitted model.

\section{Conclusions}

Based on independent tree sectioning data, graphic techniques and statistical methods were applied to validate the regionalized variable-exponent taper equations fitted for white spruce in Alberta. The results showed that the taper equations behaved well in making predictions for diameter inside bark, gross total volume, merchantable height, and merchantable volume. The averages of the prediction errors were small, and were very close to zero. The precisions of predictions were reasonably high, and were compatible with those obtained on the model fitting data. The plots of prediction errors against the predicted values revealed that the fluctuations of the prediction errors across the size classes of the predicted values were reasonably small, and could generally be considered as consistent. Based on these, it is concluded that the regionalized Kozak's taper equations developed for white spruce function successfully in their intended operating environment in Alberta, and the resulting fit statistics from the model fitting data provide an adequate indication of how well the taper equations will predict in future applications.

\section{References}

Alberta Forest Service. 1988. Alberta phase 3 forest inventory: tree sectioning manual. Forest Measurement Sect., Alberta Forest Service, Edmonton. Publ. No. T/168. (Revised 1988 [formerly ENF Rep. Dep. 56]).

Balci, O., and R.G. Sargent. 1984. A bibliography on the credibility assessment and validation of simulation and mathematical models. Simuletter 15(3): 15-27.

Berk, K.N. 1984. Validating regression procedures with new data. Technometrics 26: 331-338.

Burk, T.E. 1990. Prediction error evaluation: preliminary results. In L.C. Wensel and G.S. Biging (eds.). Forest Simulation Systems. Proc. of IUFRO Conf., Nov. 2-5, 1988, Univ. of California, Berkeley, CA. pp. 81-88.

Ek, A., and R.A. Monserud. 1979. Performance and compasison of stand growth models based on individual tree and diameter-class growth. Can. J. For. Res. 9: 231-244.

Freese, F. 1960. Testing accuracy. For. Sci. 6: 139-145.

Gál, J., and I.E. Bella. 1995. Evaluation of stem taper functions for estimating log volume assortment. For. Chron. 71(6): 743-746.
Huang, S. 1994. Individual tree volume estimation procedures for Alberta: methods of formulation and statistical foundations. Land and Forest Service, Alta. Env. Prot. Tech. Rep. Pub. No. T/288, Edmonton, Alberta.

Huang, S. 1997. Development of compatible height and site index models for young and mature stands within an ecosystem-based management framework. In Empirical and process-based models for forest tree and stand growth simulation (in press). Sept. 20-26, 1997, Oeiras, Portugal.

Huang, S., S.J. Titus, and G. Klappstein. 1997. Development of a subregion-based compatible height-site index-age model for young and mature lodgepole pine in Alberta. Land and Forest Service, For. Mgmt. Res. Note No. 6, Pub. No.T/353.

Husch, B., C.I. Miller, and T.W. Beers. 1982. Forest mensuration. 3rd. ed. John Wiley \& Sons, New York.

Keeland, B.D., and R.R. Sharitz. 1993. Accuracy of tree growth measurements using dendrometer bands. Can. J. For. Res. 23: 2454-2457.

Kozak, A. 1988. A variable-exponent taper equation. Can. J. For. Res. 18: 1363-1368.

Kozak, A. 1997. Effects of multicollinearity and autocorrelation on the variable-exponent taper equations. Can. J. For. Res. 27: 619-629.

Kozak, A., and J.H.G. Smith. 1993. Standards for evaluating taper estimating systems. For. Chron. 69: 438-444.

Montgomery, D.C., and E.A. Peck. 1992. Introduction to linear regression analysis. 2nd ed. John Wiley \& Sons, New York.

Myers, R.H. 1990. Classical and modern regression with applications. 2nd ed. PWS-KENT Publ. Co., Boston.

Neter, J., W. Wasserman, and M. Kutner. 1990. Applied linear statistical models. 3rd edition. Irwin, Homewood.

Picard, R.R., and R.D. Cook. 1984. Cross-validation of regression models. J. Am Stat. Assoc. 79: 575-583.

Pillsbury, N.H., P.M. McDonald, and V. Simon. 1995. Reliability of tanoak volume equations when applied to different areas. W. J. A. F. 10(2): 72-78.

Rawlings, J.O. 1988. Applied regression analysis - a research tool. Wadsworth, Belmont, California.

Rennie, J.C., and H.V. Wiant. 1978. Modification of Freese's chi-square test of accuracy. USDI Bureau of Land Management, Res. Invent. Note BLM 14, D340, Denver, CO.

Reynolds, M.R., Jr., Burkhart, H.E., and Daniels, R.F. 1981. Procedures for statistical validation of stochastic simulation models. For. Sci. 27: 349-364.

Reynolds, M.R., Jr., and J. Chung. 1986. Regression methodology for estimating model prediction error. Can. J. For. Res. 16: 931-938. Rykiel, E.J. 1996. Testing ecological models: the meaning of validation. Ecol. Model. 90: 229-244.

Soares, P., M. Tomé, J.P. Skovsgaard, and J.K. Vanclay. 1995. Validating growth models for forest management using continuous forest inventory data. For. Ecol. Manage. 71: 251-266.

Vanclay, J.K., and J.P. Skovsgaard. 1997. Evaluating forest growth models. Ecol. Model. 98: 1-12. 